\title{
Spectral Parameters of an Exciton in Double Semiconductor Quantum Rings in an Electric Field
}

\author{
O.M. Makhanets*, V.I. Gutsul, I.P. Koziarskyi, A.I. Kuchak
}

\author{
Yuriy Fedkovych Chernivtsi National University, 2, Kotsyubynsky St., 58002 Chernivtsi, Ukraine
}

(Received 17 February 2021; revised manuscript received 15 April 2021; published online 20 April 2021)

\begin{abstract}
The influence of a homogeneous electric field on the exciton energy spectrum and the intensity of interband quantum transitions in double semiconductor ( $\mathrm{GaAs} / \mathrm{Al}_{x} \mathrm{Ga}_{1-} \mathrm{As}$ ) cylindrical quantum rings has been studied. Assuming that the lattice constant and the dielectric constant of the nanosystem elements differ slightly from each other, a model of effective masses and rectangular potentials is used to calculate the electron and hole spectra. The corresponding stationary Schrödinger equations for non-interacting electrons and holes in the absence of an electric field are solved analytically exactly. Radial wave functions are obtained as a linear combination of the Bessel, Neumann and modified Bessel functions. The stationary Schrödinger equations for quasiparticles in the presence of an electric field are not analytically solved. For their approximate solution, the unknown wave functions are sought in the form of an expansion over a complete set of cylindrically symmetric wave functions, and the energy of an electron or a hole is found from the solution of the corresponding secular equation. Since the interaction energy between an electron and a hole is much less than the sum of the size-quantized energies of the corresponding quasiparticles, the exciton binding energy is found using perturbation theory. The dependences of the energies of an electron, a hole, and an exciton on the magnitude of the electric field strength are analyzed. It is shown that the electric field significantly affects the localization of quasiparticles in the system of double nanorings. In this case, both the energies of an electron, a hole, and an exciton and the intensities of interband quantum transitions nonmonotonically depend on the magnitude of the electric field strength.
\end{abstract}

Keywords: Nanoring, Exciton, Energy spectrum, Intensity, Electric field.

\section{INTRODUCTION}

For the first time, semiconductor quantum rings were grown by molecular beam epitaxy by T. Mano et al. [1]. In this work, the authors obtained ordered arrays of concentric double quantum rings based on GaAs and $\mathrm{Al}_{x} \mathrm{Ga}_{1-x} \mathrm{As}$ semiconductors and experimentally investigated the photoluminescence spectra in them.

In terms of practical use, quantum rings are used in photodetectors [2], semiconductor lasers [3], as elementary qubits of quantum computers [4], and memory devices.

Theoretical models for calculating the spectra of basic quasiparticles (electrons, phonons, excitons etc.) and their interaction with each other and external electric and magnetic fields in such nanosystems are also intensively developed and improved [5-11].

The influence of a magnetic field on the optical properties of semiconductor quantum rings was theoretically studied in [5-7]. The authors investigated the dependence of the electron energy spectrum on the induction of a homogeneous magnetic field in double quantum rings based on $\mathrm{GaAs} / \mathrm{Al}_{x} \mathrm{Ga}_{1}{ }_{x} \mathrm{As}$ semiconductors. In particular, they showed that, depending on the value of the induction and the thickness of the nanorings, an electron in the ground state can be localized either in the inner or outer ring. The probability of electron localization in different regions of a multilayer nanosystem does not depend on the thickness of the potential barrier separating the nanorings at arbitrary induction values.

In [8-11], the authors investigated the effect of a homogeneous electric field on the optical properties of semiconductor nanorings. In this case, the parabolic potential model was used, and the electron wave function in the electric field was sought in the form of an expansion of the full set of quasiparticle wave functions in an infinitely deep potential well with the subsequent solution of the corresponding secular equation.

In [12], we investigated the dependence of the electron energy spectrum and the oscillator forces of intraband quantum transitions on the electric field strength $(F)$ in a system of double cylindrical nanorings. It was shown that the electron energies and the oscillator strengths of intraband quantum transitions nonmonotonically depend on the magnitude of the electric field strength. In particular, anticrossings of energy levels are observed in the dependences of energies on $F$, and maxima and minima are clearly expressed in the dependences of oscillator forces on $F$.

The aim of this work is to build one of the possible theoretical approaches to solving the problem of the exciton spectrum and the intensity of interband quantum transitions in double semiconductor quantum rings in a constant electric field. The theory developed here makes it possible to analyze the dependence of the spectral parameters of an electron, a hole and an exciton on the magnitude of the strength $F$.

\section{THEORY OF THE EXCITON SPECTRUM AND INTENSITIES OF INTERBAND QUANTUM TRANSITIONS IN DOUBLE NANORINGS IN AN ELECTRIC FIELD}

\footnotetext{
*makhanets.oleksandr@gmail.com
} 


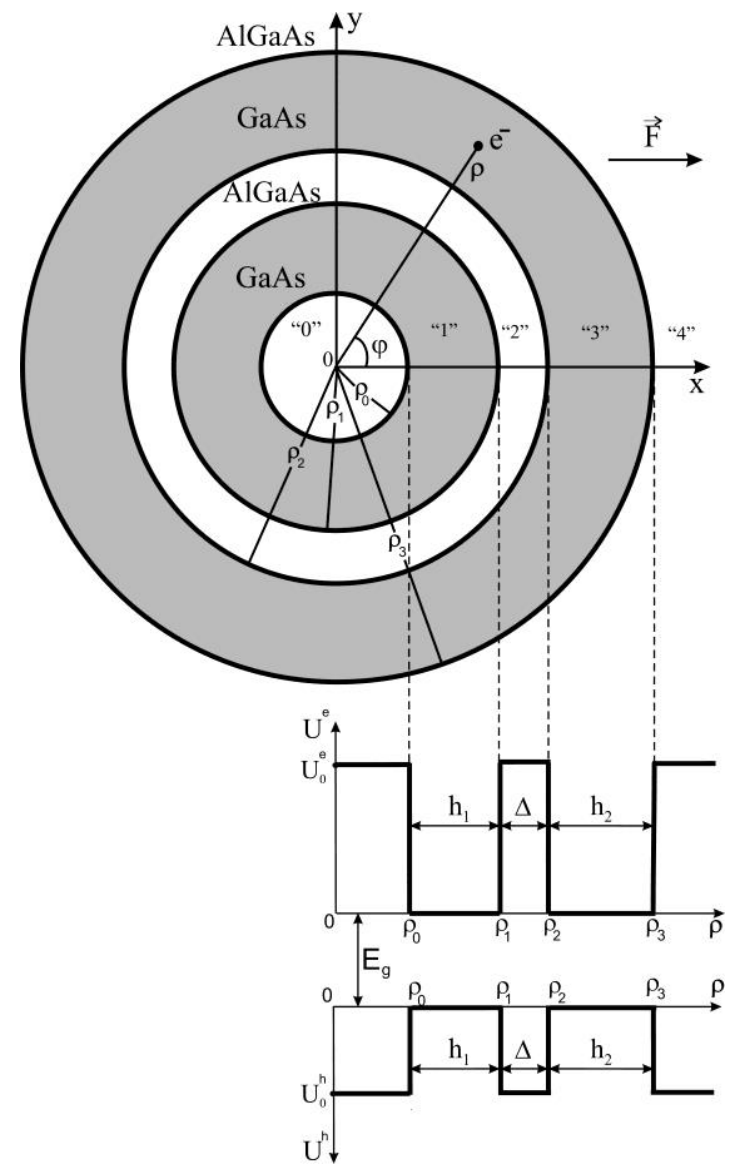

Fig. 1 - Geometric and energy schemes of the nanosystem

In this work, we investigate a system consisting of two concentric nanorings of height $L$ (GaAs quantum wells), which are separated from each other by a concentric and tunnel-transparent $\mathrm{Al}_{x} \mathrm{Ga}_{1-x} \mathrm{As}$ nanoring of thickness $\Delta$. The inner and outer radii of the first ring are $\rho_{0}$ and $\rho_{1}$ (thickness $h_{1}$ ), of the second ones are $\rho_{2}$ and $\rho_{3}$ (thickness $h_{2}$ ). The cross-section by the plane $z=0$ and the energy diagram of such a nanosystem are

$$
\hat{H}_{i}\left(\vec{r}_{i}\right)=\frac{1}{2 \mu^{(i)}\left(\rho_{i}\right)}\left[-\hbar^{2}\left(\frac{\partial^{2}}{\partial \rho_{i}^{2}}+\frac{1}{\rho_{i}} \frac{\partial}{\partial \rho_{i}}+\frac{1}{\rho_{i}^{2}} \frac{\partial^{2}}{\partial \phi_{i}^{2}}\right)\right]-\frac{\hbar^{2}}{2 \mu^{(i)}\left(\rho_{i}\right)} \frac{\partial^{2}}{\partial z_{i}^{2}}+U^{(i)}\left(\vec{r}_{i}\right) \mp|e| F \rho_{i} \cos \phi_{i},(i=e, h)
$$

are the Hamiltonians of non-interacting electron and hole (in the last term, the sign "-" refers to the electron, and "+" - to the hole);

$$
U\left(\left|\vec{r}_{e}-\vec{r}_{h}\right|\right)=-\frac{e^{2}}{\varepsilon\left(\vec{r}_{e}, \vec{r}_{h}\right)\left|\vec{r}_{e}-\vec{r}_{h}\right|}
$$

is the potential energy of interaction of the electron and the hole in a medium with dielectric constant $\varepsilon\left(\vec{r}_{e}, \vec{r}_{h}\right)$, which in the general case is a complex function that depends on the spatial location of the electron and the hole in the nanosystem. Note that in the case of the investigated nanosystem based on $\mathrm{GaAs}_{\mathrm{A}} / \mathrm{Al}_{x} \mathrm{Ga}_{1-x} \mathrm{As}$ semiconductors, the dielectric constants of the contacting media are very close. Therefore, the system of quantum nanorings can always be considered as a continuum with a constant average dielectric constant $\bar{\varepsilon}=\left(\varepsilon_{0}+\varepsilon_{1}\right) / 2$ shown in Fig. 1. The electric field strength vector $\vec{F}$ is directed along the $O x$ axis.

For reasons of symmetry, it is convenient to perform all further calculations in a cylindrical coordinate system $(\rho, \varphi, z)$ with the $O z$ axis along the axial axis of the nanorings.

Assuming that the lattice constants and the dielectric constants of the nanosystem elements differ slightly from each other, a model of effective masses and rectangular potentials is used to calculate the electron and hole spectra. These values are considered known in all areas of the nanosystem:

$$
\begin{aligned}
& \mu^{(e, h)}(\vec{r})= \begin{cases}\mu_{0}^{(e, h)}, & 0 \leq \rho \leq \rho_{0}, \rho_{1} \leq \rho \leq \rho_{2}, \rho>\rho_{3}, \\
\mu_{1}^{(e, h)}, & \rho_{0}<\rho<\rho_{1}, \rho_{2}<\rho \leq \rho_{3},\end{cases} \\
& U^{(e, h)}(\rho)= \begin{cases}U_{0}^{(e, h)}, 0 \leq \rho \leq \rho_{0}, \rho_{1} \leq \rho \leq \rho_{2}, \rho>\rho_{3}, \\
0, \rho_{0}<\rho<\rho_{1}, \rho_{2}<\rho \leq \rho_{3} .\end{cases}
\end{aligned}
$$

Taking into account that the electric field does not affect the energy spectrum of the electron when it moves along the $\mathrm{Oz}$ axis, we will consider it impossible for the quasiparticle to enter the region of the rings $|z|>L / 2$. Therefore

$$
U^{(e, h)}(z)= \begin{cases}\infty, & |z|>L / 2 \\ 0, & |z| \leq L / 2 .\end{cases}
$$

In order to investigate the exciton states in such a nanosystem, it is necessary to solve the stationary Schrödinger equation

$$
\hat{H}_{e x}\left(\vec{r}_{e}, \vec{r}_{h}\right) \Psi_{e x}\left(\vec{r}_{e}, \vec{r}_{h}\right)=E_{e x} \Psi_{e x}\left(\vec{r}_{e}, \vec{r}_{h}\right)
$$

with Hamiltonian

$$
\hat{H}_{e x}\left(\vec{r}_{e}, \vec{r}_{h}\right)=E_{g}+\hat{H}_{e}\left(\vec{r}_{e}\right)+\hat{H}_{h}\left(\vec{r}_{h}\right)+U\left(\left|\vec{r}_{e}-\vec{r}_{h}\right|\right),
$$

where $E_{g}$ is the band gap of the material of the quantum wells of the nanosystem;

It is clear that the Schrödinger equation (4) with Hamiltonian (5) cannot be exactly solved. We will seek its approximate solution in two stages. Taking into account that the energy of interaction between the electron and the hole is much less than the energy of their dimensional quantization, we first find the latter, taking into account the influence of the electric field, and then, using perturbation theory, we take into account the interaction potential of both quasiparticles (7).

Thus, in a cylindrical coordinate system we will solve the stationary Schrödinger equations for noninteracting electron and hole

$$
\hat{H}_{i} \Psi_{i}\left(\rho_{i}, \phi_{i}, z_{i}\right)=E_{i} \Psi_{i}\left(\rho_{i}, \phi_{i}, z_{i}\right),(i=e, h) .
$$

The methods for solving (8) for an electron and a hole are completely equivalent. Therefore, we will give it as an example of an electron, temporarily omitting the subscript " $i "$. 
As can be seen from (3) and the form of the Hamiltonian (6), the variable $z$ in the corresponding Schrödinger equation (8) is separated, and the wave function of the electron can be found in the form

$$
\Psi(\vec{r})=F(\rho, \phi) f_{n_{z}}(z),
$$

where

$$
f_{n_{z}}(z)= \begin{cases}\cos \left(\frac{\pi n_{z}}{L} z\right), & n_{z}=1,3,5, \ldots \\ \sin \left(\frac{\pi n_{z}}{L} z\right), & n_{z}=2,4,6, \ldots\end{cases}
$$

The Schrödinger equation with the Hamiltonian (6) in the absence of an electric field $(F=0)$ is solved exactly

$$
F_{n_{\rho} m}^{0}(\rho, \phi)=\frac{1}{\sqrt{2 \pi}} R_{n_{\rho} m}(\rho) e^{i m \phi}
$$

Here $n_{\rho}$ and $m$ are, respectively, the radial and magnetic quantum numbers, and radial wave functions have the form

$$
\begin{gathered}
R_{n_{\rho} m}^{(i)}(\rho)=A_{n_{\rho} m}^{(i)} j_{m}^{(i)}(\chi \rho)+B_{n_{\rho} m}^{(i)} n_{m}^{(i)}(\chi \rho), \\
(i=0,1,2,3,4), \\
j_{m}^{(i)}(\chi \rho)= \begin{cases}I_{m}\left(\chi_{0} \rho\right), & i=0,2,4 \\
J_{m}\left(\chi_{1} \rho\right), & i=1,3\end{cases} \\
n_{m}^{(i)}(\chi \rho)= \begin{cases}K_{m}\left(\chi_{0} \rho\right), & i=0,2,4 \\
N_{m}\left(\chi_{1} \rho\right), & i=1,3\end{cases}
\end{gathered}
$$

where $J_{m}, N_{m}$ are the cylindrical Bessel functions of the first and second kind, $I_{m}, K_{m}$ are the cylindrical modified Bessel functions of the first and second kind,

$$
\begin{gathered}
\chi_{0}=\sqrt{2 \mu_{0}\left(U_{0}-E_{n_{\rho} m}^{0}\right) / \hbar^{2}+\pi^{2} n_{z}^{2} / L^{2}} \\
\chi_{1}=\sqrt{2 \mu_{1} E_{n_{\rho} m}^{0} / \hbar^{2}-\pi^{2} n_{z}^{2} / L^{2}}
\end{gathered}
$$

All unknown coefficients $A_{n_{\rho m}}^{(i)}, B_{n_{\rho m}}^{(i)}$ (hence the wave functions) and electron energies $E_{n_{\rho} m}^{0}$ are found from the conditions of continuity of wave functions (12)-(14) and probability density fluxes at the heterointerfaces of the nanostructure and the conditions of normalization of the radial wave function.

In this case, from the conditions of finiteness of the wave function at $\rho=0$ and $\rho \rightarrow \infty$, it follows that the coefficients $B_{n_{\rho} m}^{(0)}=0, A_{n_{\rho} m}^{(4)}=0$.

In the case, when an external electric field is applied to the system, the Schrödinger equation with the Hamiltonian (6) is not analytically solved.

To find the electron energy spectrum at $F \neq 0$, we write down unknown wave functions in the form of an expansion of the full set of wave functions (9)

$$
F_{n}(\rho, \phi)=\frac{1}{\sqrt{2 \pi}} \sum_{n_{\rho}} \sum_{m} c_{n_{\rho} m}^{n} R_{n_{\rho} m}(\rho) e^{i m \phi} .
$$

Substituting expansion (15) into the Schrödinger equation with the Hamiltonian (6), we obtain the secular equation:

$$
\left|H_{n_{\rho} m, n_{\rho}^{\prime} m^{\prime}}-E_{n n_{z}} \delta_{n_{\rho}, n_{\rho}^{\prime}} \delta_{m, m^{\prime}}\right|=0,
$$

where the matrix elements $H_{n_{\rho} m, n_{\rho}^{\prime} m^{\prime}}$ have the following form:

$$
H_{n_{\rho} m, n_{\rho}^{\prime} m^{\prime}}=E_{n_{\rho} m} \delta_{n_{\rho}, n_{\rho}^{\prime}} \delta_{m, m^{\prime}}+\left(\delta_{m^{\prime}, m+1}+\delta_{m^{\prime}, m-1}\right) \frac{e F}{2} \int_{0}^{\infty} R_{n_{\rho} m}(\rho) R_{n_{\rho}^{\prime} m^{\prime}}(\rho) \rho^{2} d \rho .
$$

Note that, as seen from (13) and (14), the new states of the electron in its transverse motion are now characterized by only one quantum number $n$.

The problem of finding the energy spectrum $E_{n}$ and the wave functions $F_{n}(\rho, \varphi)$ is now reduced to the calculation of the eigenvalues and eigenvectors of the obtained matrix.

Thus, both the full wave functions of the electron $\psi_{n^{e} n_{z}^{e}}^{e}(\vec{r})$ (9) and its energy $E_{n^{e} n_{z}^{e}}^{e}$ are now known. The wave functions $\left(\psi_{n^{h} n_{z}^{h}}^{h}(\vec{r})\right)$ and the energy $\left(E_{n^{h} n_{z}^{h}}^{h}\right)$ of the hole are obtained in a similar way.

The electron and hole energies found taking into account dimensional quantization and the electric field make it possible to determine the spectrum of exciton energies in double quantum rings according to perturbation theory

$$
E_{n^{h} n_{z}^{h}}^{n^{e} n_{z}^{e}}=E_{g}+E_{n^{e} n_{z}^{e}}^{e}+E_{n^{h} n_{z}^{h}}^{h}+\Delta E_{n^{h} n_{z}^{h}}^{n^{e} n_{z}^{e}}
$$

where

$$
\Delta E_{n^{h} n_{z}^{n_{h}^{e}}}^{n^{e} n_{z}^{e}}=-\frac{e^{2}}{\bar{\varepsilon}} \int d^{3} \vec{r}_{e} \int d^{3} \vec{r}_{h} \frac{\left|\psi_{n^{e} n_{z}^{e}}^{e}(\vec{r}) \psi_{n^{h} n_{z}^{h}}^{h}(\vec{r})\right|^{2}}{\left|\vec{r}_{e}-\vec{r}_{h}\right|}
$$

is the binding energy of the electron and the hole in the corresponding quantum states.

The obtained energies and wave functions of the electron also make it possible to estimate the intensities of interband optical quantum transitions using formula (15)

$$
I_{n^{h} n_{z}^{h}}^{n^{e} n_{z}^{e}}=\left|\int \psi_{n^{e} n_{z}^{e}}^{e}(\rho, \phi, z) \psi_{n^{h} n_{z}^{h}}^{h}(\rho, \phi, z) \rho d \rho d \phi d z\right|^{2} .
$$

Further calculation and analysis of the exciton spectrum and intensities of interband quantum transitions are performed by numerical methods.

\section{ANALYSIS AND DISCUSSION OF RESULTS}

The dependence of the electron, hole, and exciton spectra and the intensities of interband optical quantum transitions on the magnitude of the electric field strength $(F)$ was studied on the example of double nanorings $\mathrm{GaAs} / \mathrm{Al}_{0.4} \mathrm{Ga}_{0.6} \mathrm{As}$ with the following physical parameters: $E_{g}=1424 \mathrm{meV}, \varepsilon_{0} \approx \varepsilon_{1}=13, \mu_{0}^{e}=0.096 m_{0}$, $\mu_{1}^{e}=0.063 m_{0}, U_{0}^{e}=297 \mathrm{eV}, \mu_{0}^{h}=0.61 m_{0}, \mu_{1}^{h}=0.51 m_{0}$, $U_{0}^{h}=224 \mathrm{meV}$ ( $m_{0}$ is the electron mass in vacuum); the lattice constant of the medium GaAs $a_{\mathrm{GaAs}}=5.65 \AA$. 
Since all subsequent calculations of the spectral parameters of the electron were performed for the quantum number $n_{z}=1$, it is further omitted for convenience.

Fig. 2 shows that the energy of the ground state of the electron and the hole only decreases with increasing $F$. However, this is no longer the case for excited states. In particular, the electron energy in the state with $n^{e}=5$ increases with increasing $F$. In the general case, an increase or decrease in the energies of an electron or a hole with increasing $F$ is due to the nanoring in which the electron is located in the corresponding states and the nature of the angular probability distribution relative to the direction of the electric field. Since the effective mass of the hole is almost an order of magnitude greater than the electron mass, the density of its energy levels in the energy scale of the quantum well is significant, and pronounced anticrossings

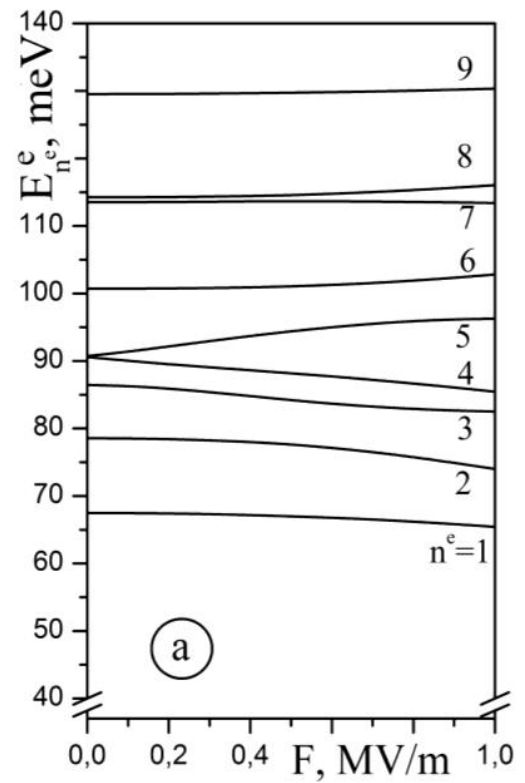

are observed in the corresponding dependences on $F$ (Fig. 2b). The cause of anticrossing is a change in the localization of the quasiparticle between the outer and inner rings in adjacent quantum states with increasing electric field strength [12].

The inset in Fig. 3a shows the dependence of the binding energy of the exciton ground state on $F$ for the same geometric parameters of the nanosystem.

Fig. 3 shows that the exciton binding energy is maximal in the absence of an electric field. It only decreases with increasing $F$ and is almost zero at $F=0.5 \mathrm{MV} / \mathrm{m}$. This behavior of $\Delta E_{1}^{1}$ is easy to understand by considering the dependence of the probability density of finding an electron and a hole in a nanosystem in the ground state at $F=0$, where $\Delta E_{1}^{1}$ is maximum and $F=0.5 \mathrm{MV} / \mathrm{m}$, where it is minimal.

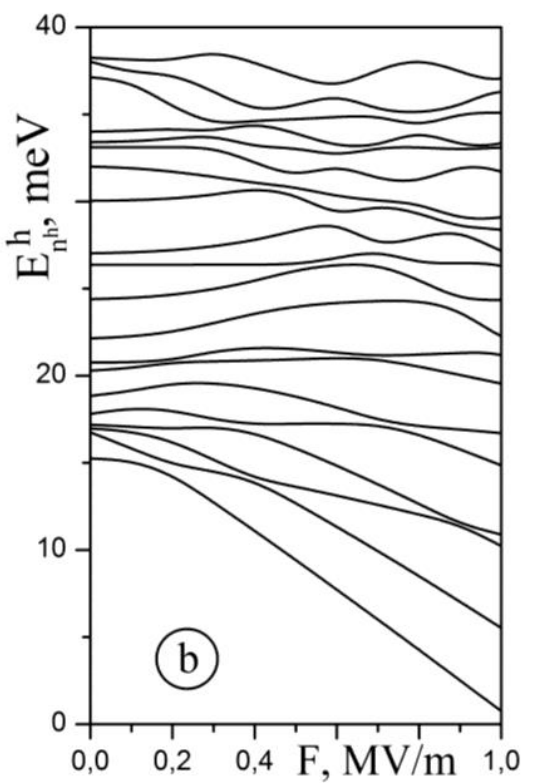

Fig. 2 - Dependences of the energies of the electron $E_{n^{e}}^{e}$ (a) and the hole $E_{n^{h}}^{h}$ (b) on the magnitude of the electric field strength $(F)$ at $L=5 \mathrm{~nm}, \rho_{0}=5 a_{\mathrm{GaAs}}, h_{1}=18 a_{\mathrm{GaAs}}, \Delta=3 a_{\mathrm{GaAs}}, h_{2}=17 a_{\mathrm{GaAs}}$
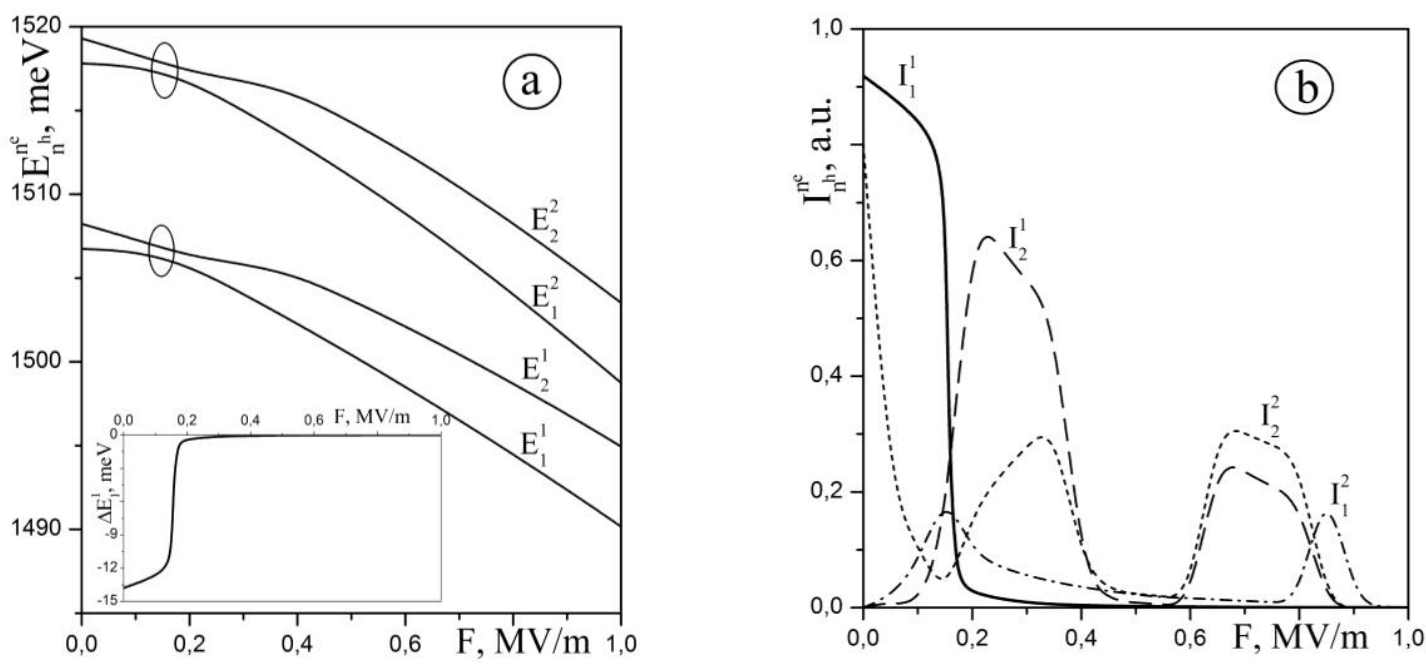

Fig. 3 - Dependences of the energies of several lowest exciton levels $E_{n^{h}}^{n^{e}}$ (a) and intensities of interband optical quantum transitions $I_{n^{h}}^{n^{e}}$ (b) on the magnitude of the electric field strength $(F)$ at $L=5 \mathrm{~nm}, \rho_{0}=5 a_{\mathrm{GaAs}}, h_{1}=18 a_{\mathrm{GaAs}}, \Delta=3 a_{\mathrm{GaAs}}, h_{2}=17 a_{\mathrm{GaAs}}$ 
At $F=0$, the electron and the hole in the ground state are localized in the inner nanoring. In this case, the overlap of the corresponding wave functions in (19) is significant, and the effective distance between the quasiparticles is small.

The hole begins to tunnel into the outer nanoring with increasing electric field strength. In this case, the effective distance between the quasiparticles increases and the binding energy decreases. At $F=0.5 \mathrm{MV} / \mathrm{m}$, the hole is completely localized in the outer ring, and the electron - in the inner one. The wave functions in the corresponding states overlap weakly and the binding energy is low.

This circumstance is responsible for absolutely similar behavior of the intensity of the quantum transition $I_{1}^{1}$ (Fig. 3b). It is maximum at $F=0$ and only decreases with increasing $F$. The dependences of the transitions intensities $I_{n^{h}}^{n^{e}}$ between other quantum states on $F$ are nonmonotonic functions with pronounced maxima and minima. This behavior is due to the change in the hole localization between the outer and inner nanorings in excited states. The number of maxima is determined by the number of anticrossings of hole energy levels (see Fig. 2b).

Note that the binding energy of the exciton is much less than the sum of size-quantized energies of the electron and the hole. Therefore, the dependence of the energies of the exciton states on the strength $F$ (see Fig. $3 b$ ) is mainly due to the peculiarity of the behavior of the energies of the electron and hole and their overall contribution to (18). In particular, in these dependences, exciton anticrossing is observed as a manifestation of anticrossing of hole energy levels.

\section{CONCLUSIONS}

The dependence of the energy spectrum of an electron, a hole, an exciton, and the intensities of interband quantum transitions on the magnitude of the electric field strength $(F)$ in binary quantum nanorings based on GaAs/Al ${ }_{0.4} \mathrm{Ga0} .6 \mathrm{As}$ semiconductors was investigated in the model of effective masses and rectangular potentials.

To calculate the energy spectrum and distributions of the probability density of finding an electron and a hole in nanorings in an electric field, the stationary Schrödinger equation is solved by decomposing an unknown wave function by wave functions of a quasiparticle in a nanosystem in the absence of an external field.

The energies of the hole, the exciton, and the intensity of the interband quantum transitions depend nonmonotonically on the magnitude of the electric field strength $F$. In particular, in the energy dependences on $F$, anticrossings of energy levels are observed, and in the dependences of the oscillator forces on $F$ (except for the exciton ground state) pronounced maxima and minima are observed. The reason for this behavior is a change in the localization of the electron and the hole in the space of two nanorings in different quantum states with a change in the electric field strength.

\title{
REFERENCES
}

1. T. Kuroda, T. Mano, T. Ochiai, S. Sanguinetti, K. Sakoda, G. Kido, N. Koguchi, Phys. Rev. B 72, 205301 (2005).

2. J.H. Dai, Y. Lin, S.Ch. Lee, IEEE Photon. Technol. Lett. 19 No 19, 1511 (2007).

3. F. Suarez, D. Granados, M.L. Dotor, J.M. Garcia, Nanotechnology 15, S126 (2004).

4. M. Szopa, E. Zipper, J. Phys.: Conf. Series 213, 012006 (2010).

5. F.J. Culchac, N. Porras-Montenegroa, J.C. Granadaa, A. Latge, Microelectron. J. 39, 402 (2008).

6. F.J. Culchac, N. Porras-Montenegroa, A. Latge, J. Phys.: Condens. Matter 20, 285215 (2008).

7. M.V. Zdorovets, A.A. Mashentseva, A.L. Kozlovskiy, I.A. Ivanov, K.K. Kadyrzhanov, J. Nano- Electron. Phys. 9 No 6, 06017 (2017).

8. C.M. Duque, Ruben E. Acosta, A.L. Morales, M.E. MoraRamos, R.L. Restrepo, J.H. Ojeda, E. Kasapoglu, C.A. Duque, Opt. Mater. 60, 148 (2016).

9. H.M. Baghramyan, M.G. Barseghyan, D. Laroze, A.A. Kirakosyan, Physica E 77, 81 (2016).

10. M.G. Barseghyan, Physica E 69, 219 (2015).

11. T. Chakraborty, A. Manaselyan, M. Barseghyan, D. Laroze, Phys. Rev. B 97, 041304(R) (2018).

12. O.M. Makhanets, V.I. Gutsul, A.I. Kuchak, Condens. Matter Phys. 21 No 4, 43704 (2018).

\section{Спектральні параметри екситона в подвійних напівпровідникових квантових кільцях в електричному полі}

\author{
О.М. Маханець, В.І. Гуцул, І.П. Козярський, А.І. Кучак
}

Чернівецький національний університет іл. Ю. Федьковича, вул. Коцюбинського, 2, 58002 Чернівиі, Украӥна

Досліджено вплив однорідного електричного поля на енергетичний спектр екситона та інтенсивності міжзонних квантових переходів у подвійних напівпровідникових $\left(\mathrm{GaAs}_{\mathrm{s}} / \mathrm{Al}_{x} \mathrm{Ga}_{1-x} \mathrm{As}\right)$ циліндричних квантових кільцях. Вважаючи, що сталі гратки і діелектричні проникності елементів наносистеми слабко відрізняються між собою, для розрахунку спектрів електрона і дірки використовуеться модель ефективних мас і прямокутних потенціалів. Відповідні стаціонарні рівняння Шредінгера для невзаемодіючих між собою електрона і дірки за відсутності електричного поля розв'язуються аналіти чно точно. Радіальні хвильові функції отримуються у вигляді лінійної комбінації функцій Бесселя, Неймана та модифікованих функцій Бесселя. Стаціонарні рівняння Шредінгера для квазічастинок за наявності електричного поля аналітично не розв'язуються. Для їх наближеного розв’язку невідомі хвильові функції шукаються у вигляді розкладу за повним набором циліндрично-симетричних хви- 
льових функцій, а енергія електрона чи дірки знаходиться із розв'язування відповідного секулярного рівняння. Оскільки енергія взаемодії між електроном і діркою набагато менша, ніж сума розмірноквантованих енергій відповідних квазічастинок, то енергія зв'язку екситона знаходиться з використанням теорії збурень. Проаналізовано залежності енергій електрона, дірки й екситона від величини напруженості електричного поля. Показано, що електричне поле суттево впливае на локалізацію квазічастинок у системі подвійних нанокілець. При цьому як енергії електрона, дірки й екситона, так й інтенсивності міжзонних квантових переходів немонотонно залежать від величини напруженості електричного поля.

Ключові слова: Нанокільце, Екситон, Енергетичний спектр, Інтенсивність, Електричне поле. 